\title{
Decentralised Control Optimisation for a Glass Furnace by SGA's
}

\author{
Kumaran Rajarathianm, J. Barry Gomm, Karl Jones, Ahmed Saad Abdelhadi
}

\begin{abstract}
In this paper, the potential of standard genetic algorithms (SGAs) are presented to optimise the discrete PID parameters for multivariable glass furnace. Control oriented models of each multivariable glass furnace; glass temperature and excess oxygen are used to optimise the discrete controller with personalised cost function and adjusted boundaries by SGAs, individually. Well optimised discrete PID parameters by control oriented model are applied to realistic multivariable model by decentralised method.
\end{abstract}

Key words: Genetic Algorithms, Discrete Control Optimisation, and Decentralised Control.

\section{INTRODUCTION}

Glass manufacturing processes have really long dynamics and are complex processes with high energy usage. Especially, large furnaces with multiple port burners cause the glass manufacturing industries to consume high energies in glass production. Most glass industries are operating at maximum daily through-put to fulfil the market requirement. Therefore, glass furnace operations are facing great challenges in reduction of fuel consumption by applying well tuned control strategies. Apart from high energy consumption, undesirable emission from glass industries is another setback to consider as the entire world is greatly concerned about green house effects. Tight environmental regulations are now applied to reduce gases and particles that are undesirable emissions associated with burning fossil fuels.

Generally, the glass industries are operating within the emission guideline which was regulated by environmental agencies [1]. Thus, most glass industries are not emphasising on continuous monitoring and control strategies for emissions. At maximum operating conditions, the percentage of producing undesirable emission is high. If there is any occurrence of sudden undesirable disturbances this can result in more problems for existing furnaces which is already operating in poor thermal conditions around the world. For such a complex multivariable process, the decentralised controls strategy is generally applied and has always been in the attention of many researchers for developing a precise control strategy to enhance the performance of multivariable processes. However, difficulties are encountered in designing the decentralised control due to the loop interactions.

A literature search reveals that there are several classified tuning methods suggested to tune decentralised controllers for multivariable processes such as Detuning method [2], Sequential design method [3], and Iterative method [4]. These tuning methods have achieved a certain degree of success in the design approach. However, these tuning methods do exhibit weaknesses and can suffer in compensating the couplings between loop-interactions of a multivariable system. To improve the compensation of loopinteractions, the effective open-loop method (EOP) was introduced [5]. But, the EOP method produces model approximation error due to the mathematical complications as the model dimensions increased. In recent years, to improve the entire control performance and robust stability, a systematical approach based on the generalised IMC-PID design method [6] and the reduced effective transfer function (RETF) by inverse response behaviour method [7] is introduced for multivariable process. But, both methods involve a complex mathematical approach to design the decentralised controllers. 
However, a question always arises about the wellness of control optimisation and the flexibility due to the application constraints by those design methods. Standard Genetic algorithms (SGAs) are global search method by genetics evolution with higher performance in control optimization over traditional methods. Due to its superior selfadjustable ability, SGAs have been applied extensively in tuning the PID parameters for single-input single-output (SISO) systems [8], curve fitting [9], and fuzzy optimisation [10]. On the other hand, multiple-input multiple-output (MIMO) system is still an open research topic for optimising control parameters by SGAs. A promising decentralised controller by SGAs was proposed for multivariable process [11]. The controller performance was defined by closed-loop response in terms of time-domain bounds for both reference following and loop interactions. An integrity theorem with SGAs to enhance the closed-loop system stability when certain loops are failing or break down was proposed [12].

This paper explores the potential of SGAs in optimising the discrete PID parameters by decentralised control technique for a multivariable process without further tuning required. Further, the minimisation of fuel consumption for multivariable glass furnace is analysed by decentralised technique while maintaining a desired glass temperature. The structure of this paper is as followed; first, a brief introduction is given about the identified control oriented and realistic models of the considered multivariable glass furnace. Second, a discussion of discrete PID parameter optimisation by decentralised technique by SGAs with boundary constraints and personalised cost function. Third, a discussion of applying decentralising control technique on a realistic model. The proposed methods are developed and tested in simulations based on Matlab/Simulink models.

\section{INTRODUCTION OF MULTIVARIABLE GLASS PROCESS}

Figure 1 illustrates the block diagram of multivariable glass furnace which consists of a 24 state-space furnace model with feedback-loop and excess oxygen model. $f_{1}$ and $f_{2}$ are algebraic expressions, $f_{1}$ includes controller output and saturation, $f_{2}$ includes specific heat $(\mathrm{Cp})$ and lower heat value (LHV) for determining the combustion energy, $\mathrm{C}_{g}$ is glass control, $\mathrm{T}_{\mathrm{SET}}$ is primary temperature setting, AFR is air-fuel ratio, $\mathrm{T}_{\mathrm{amb}}$ is ambient temperature, $u$ is control output, $\dot{m}$ is fuel flow, $\mathrm{T}_{\mathrm{g}}$ is glass temperature and $\mathrm{EO}_{2}$ is excess oxygen.

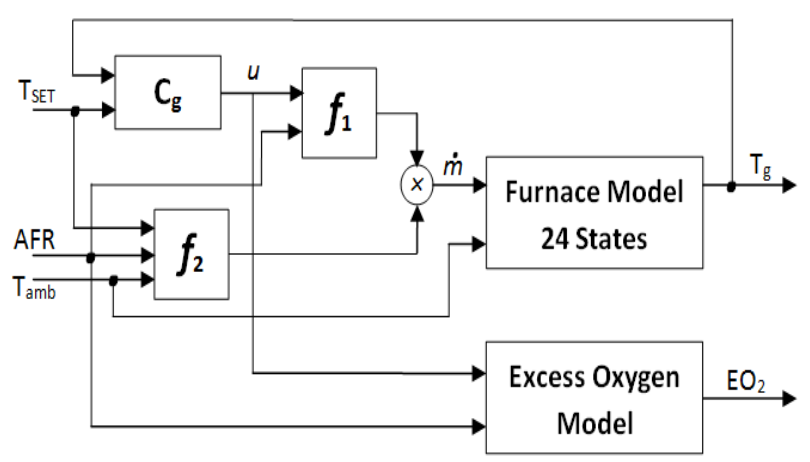

Figure 1: Block diagram of multivariable glass furnace

The realistic glass furnace model that identified and applied for further research here is representing a real plant of combustion chamber from Fenton Art Glass Company, USA [13]. This is an extended research work of radiative zone method by Holladay [14] and was identified to develop 24 state space variables (zones) model. The linearised energy balance equation is applied and modified with respective 24 state variables for each zones corresponding to temperatures.

Literature survey reveals that there is no $\mathrm{EO}_{2}$ realistic model for a glass furnace available for research. The realistic $\mathrm{EO}_{2}$ model designed for research here was developed using collected numerical data from an industrial furnace by open-loop step response technique. SGAs were applied for identification of a higher order transfer function $\left(3^{\text {rd }}\right.$ order) as a realistic model for $\mathrm{EO}_{2}$, and control oriented models for both glass temperature and $\mathrm{EO}_{2}$ models for control optimisation. The identified transfer functions by GAs are;

For $\mathrm{EO}_{2}$ Realistic Model,

$$
\frac{\Delta E O_{2}(s)}{\Delta A F R(s)}=\frac{1.613}{50.3 s^{3}+149.6 s^{2}+142.7 s+1} e^{-173 s}
$$


For $\mathrm{EO}_{2}$ Control Oriented Model,

$\frac{\triangle E O_{2}(s)}{\triangle A F R(s)}=\frac{1.6}{150 s+1} e^{-174 s}$

For Glass Temperature Control Oriented Model,

$\Delta T g(s)=\frac{4488.4}{199200 s+1} \cdot \Delta \dot{m}+\frac{-0.9834}{199200 s+1} \cdot \Delta T_{S E T}$

\section{DISCRETE PID PARAMETERS OPTIMISATION BY SGAS}

In general, a discrete PID controller can be described by an input-output relation expressed as [15],

$G(z)=K_{c}\left(1+\frac{1}{T_{i}} \frac{T}{2} \frac{(z+1)}{(z-1)}+T_{d} \frac{1}{T} \frac{(z-1)}{z}\right)$

where $T$ is the sampling time, and $K_{c}, T_{i}$ and $T_{d}$ denote the proportional gain, the integral gain and derivative gain, respectively. Equation (4) is expressed in the position form of the algorithm by applying finite difference approximations. For more accurate approximations the trapezoidal and backward rules are applied here to develop the discrete expressions for integral and derivative, respectively.

As illustrated in flowchart (Figure 2) and theories of the SGAs, at initial state, the chromosomes of an array of variable values to be optimised are defined:

Chromosome $=\left\{(\underbrace{K_{P}, K_{I}, K_{D}}_{T_{g}}),(\underbrace{K_{P}, K_{I}, K_{D}}_{E O_{2}})\right\}$

The coding selection was done based on the mutation rate $\left(\mathrm{M}_{\text {rate }}\right)$. According to [16], the binary code converges faster when $M_{\text {rate }}>0.6$. Thus, the binary coding was selected to encode the discrete controller parameters into binary string to generate the initial population randomly in the beginning. The length of chromosome is determined based on the binary precision:

$$
2^{m_{j}-1}<\left(b_{j}-a_{j}\right) \times 10^{4} \leq 2^{m_{j}}-1
$$

where $m_{j}$ is the number of bits, $b_{j}$ is the upper boundary and $a_{j}$ is the lower boundary of individual chromosome's searching parameter. Each chromosome's binary string is converted into an associated real value of PID parameters to propagate to the discrete PID controller. The decoding process into real value is done as;

$$
x_{j}=a_{j}+\operatorname{Dec} \times \frac{\left(b_{j}-a_{j}\right)}{2^{m_{j}}-1}
$$

where $x_{j}$ is the respective real value of chromosome and Dec is decimal value of respective binary string. A complete simulated system response of each PID set and its initial fitness value is evaluated by using defined objective function.

According to the chromosome's fitness value by a defined objective function, a new generation (offspring) is produced by the process of genetic operators. The genetic operators manipulate the binary strings of the chromosomes directly, by means of selection

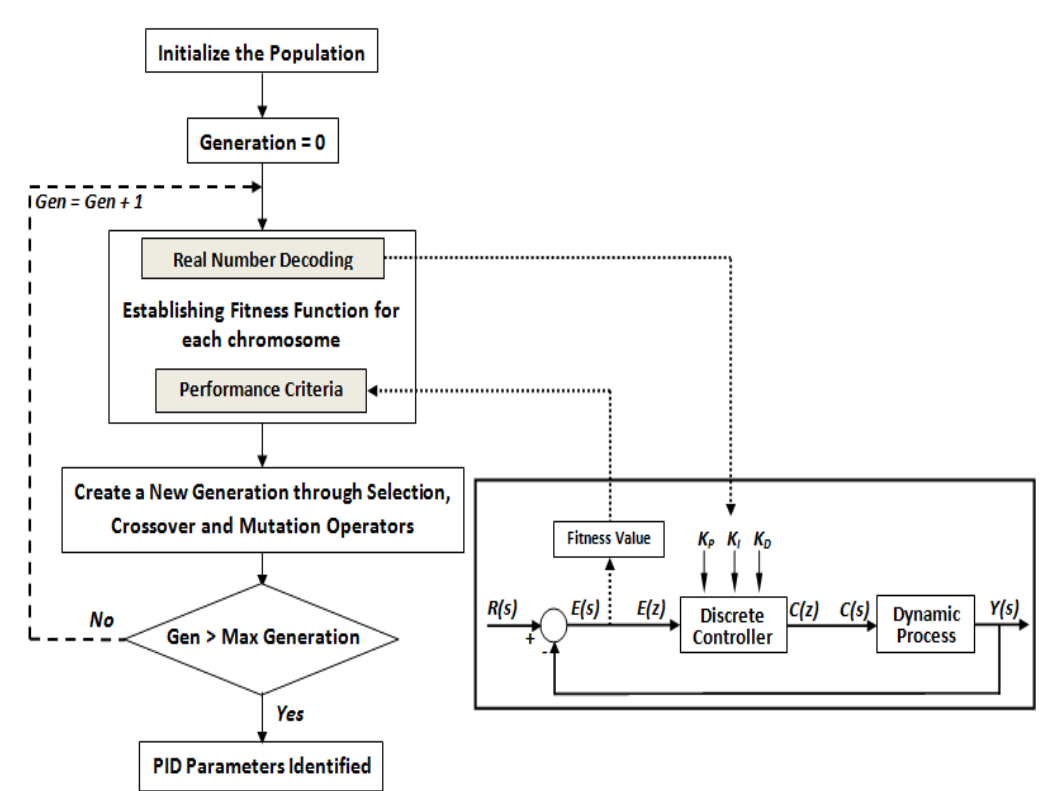

Figure 2: Flow chart of control optimisation by SGAs 
rate $\left(S_{\text {rate }}\right)$, crossover $\left(\mathrm{X}_{\text {rate }}\right)$ and mutation $\left(\mathrm{M}_{\text {rate }}\right)$ to produce a fitter chromosome for the next generation.

After the completion of genetic operator process, the new set binary string of each chromosome in the population is required to be decoded into real values and propagated again to the discrete PID controller to evaluate for a new fitness value. This process will be repeated until the end generation where the optimal fitness is attained. Since no previous information of genetic operator exists for Table 1: Selected genetic operators of $\mathrm{T}_{\mathrm{q}}$ and $\mathrm{EO}_{2}$ $\mathrm{T}_{\mathrm{g}}$ and $\mathrm{EO}_{2}$ control optimisation, the dynamic random variations of genetic operators were tested for enhancing searching mechanism, individually. Table 1 illustrates the selected genetic operator parameters for both $\mathrm{T}_{\mathrm{g}}$ and $\mathrm{EO}_{2}$.

\section{PERFORMANCE CRITERION FORMULATION}

The performance criterion for both $\mathrm{T}_{\mathrm{g}}$ and $\mathrm{EO}_{2}$ are formulated individually under closed-loop SISO control based on desired response characteristics.

i. For $T_{g}$; Overshoot $<2 \%$, Settling time $\left(T_{S}\right) \approx 5$ hrs.

ii. For $\mathrm{EO}_{2}$; Overshoot $<2 \%$, Settling time $\left(\mathrm{T}_{\mathrm{S}}\right) \approx 7 \mathrm{~min}$.

Standard objective functions (ISE and IAE) are insufficient to attain the desired response characteristics. Thus, to improve the searching mechanism, the boundary constraint is introduced by improved bound. For better selection of improved bound values, the conventional (Ziegler-Nichols and Direct Synthesis) tuning methods are analysed to identify PID values. With identified PID values, the $b_{j}$ and $a_{j}$ are adjusted accordingly to ensure an optimal solution for desired response characteristics.

Figure 3 and table 2 illustrate that the SGAs with parameter vectors of improved bound PID, $K_{P} \in[0: 1], K_{I} \in[0: 0.01], K_{D} \in[0: 50]$ of $\mathrm{EO}_{2}$ has better dynamic response and higher degree of accuracy while reducing the performance criterion by adapting the fitness value. Initial optimisation of PID parameters using conventional techniques provides better suggestion of improved bound range than assigning the bound range randomly. By limiting the $b_{j}$ of $K_{P}$, the SGA consolidates well within the boundary constraint with $K_{l}$ to converge to the global minima.

However, figure 4 and table 4 illustrate an overshoot of $10 \%$ $\left(1555^{\circ} \mathrm{K}\right)$ occurred in the transient

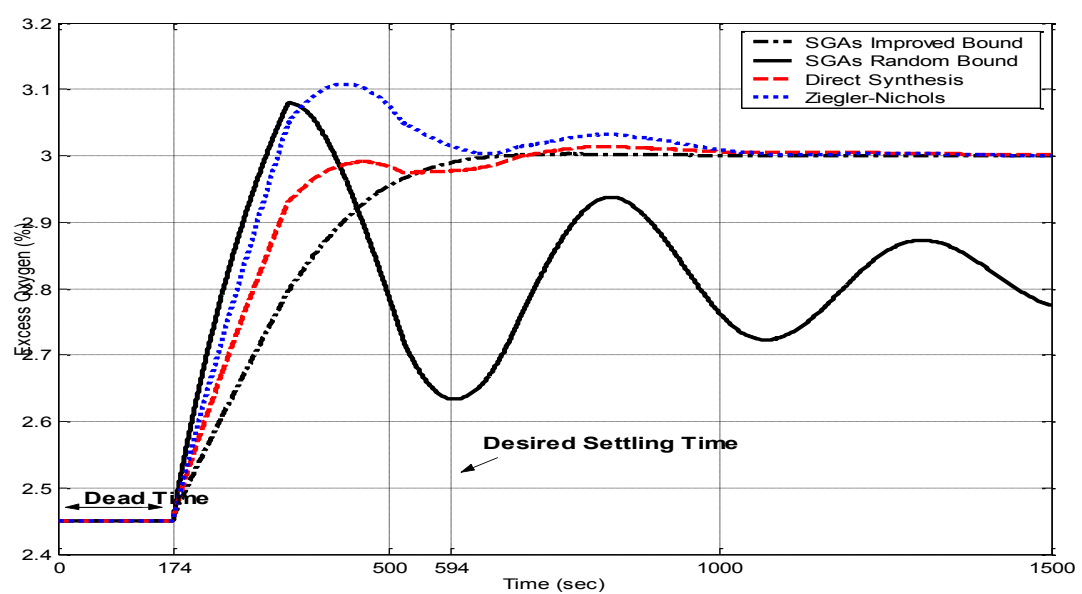

Figure 3: SGA's random and improved boundaries of $\mathrm{EO}_{2}$ responses with conventional techniques.

Table 2: PID parameters for $\mathrm{EO}_{2}$ by tuning methods

\begin{tabular}{|l|c|c|c|c|c|c|}
\hline \multicolumn{1}{|c|}{ Tuning Methods } & $\boldsymbol{K}_{\boldsymbol{P}}$ & $\boldsymbol{K}_{\boldsymbol{I}}$ & $\boldsymbol{K}_{\boldsymbol{D}}$ & $\boldsymbol{I S E}$ & $\boldsymbol{I A E}$ & $\boldsymbol{T}_{\mathbf{s}}(\mathbf{2 \%})$ \\
\hline Ziegler-Nichols & 1.38 & 0.0038 & 65.88 & - & - & $14 \mathrm{~min}$ \\
\hline Direct Synthesis & 1.137 & 0.0034 & 74 & - & - & $14.5 \mathrm{~min}$ \\
\hline Random Bound SGAs & 2 & 0 & 36.67 & 119.8 & 355.6 & - \\
\hline Improved Bound SGAs & 0.7685 & 0.0043 & 32.27 & 83.26 & 187.7 & $7.1 \mathrm{~min}$ \\
\hline
\end{tabular}


response with long settling time of $30 \mathrm{hrs}$ for $\mathrm{T}_{\mathrm{g}}$ with improved boundaries. SGAs optimise closest to the $b_{j}$ to attain the desired response characteristics, but failed to achieve global minima. To enhance the searching mechanism for the control parameters and achieve global minima the personalised cost function is applied. The weighting factor $(\lambda)$ is added with input term of cost function to minimise the fast rising effect of transient response. The personalised cost functions applied is given by relation,

$$
J_{i}(I A E+\lambda I S U)=\int_{t=0}^{t=\max }\left(|\operatorname{YoutN}(t)-1550|+\left(\lambda u^{2}\right)\right) \cdot d t
$$

where YoutN(t) is the model output and $u$ is the controller output. The selection of optimal value of $\lambda$ is done by trial and error technique. As illustrates in table 3 , the weighting factor associated with the desired response characteristics was set to be $\lambda=400$ to give more emphasis to the set point tracking objectives.

Simulation

results (Figure 4

and Table 4)

illustrate that the

SGAs with

personalised cost

\begin{tabular}{|c|c|c|c|c|}
\hline $\boldsymbol{\lambda}$ & Set-Point Error & $\boldsymbol{I A E}$ & $\boldsymbol{\lambda} \boldsymbol{I S U}$ & $\boldsymbol{T}_{\boldsymbol{s}}(\mathbf{2} \%)$ \\
\hline 100 & $1.847 \mathrm{e} 4$ & $8.783 \mathrm{e} 2$ & $1.759 \mathrm{e} 4$ & $1.9 \mathrm{hrs}$ \\
\hline 250 & $4.456 \mathrm{e} 4$ & $1.510 \mathrm{e} 3$ & $4.306 \mathrm{e} 4$ & $3.7 \mathrm{hrs}$ \\
\hline 350 & $6.173 \mathrm{e} 4$ & $1.799 \mathrm{e} 3$ & $5.993 \mathrm{e} 4$ & $4.6 \mathrm{hrs}$ \\
\hline 400 & $7.029 \mathrm{e} 4$ & $1.922 \mathrm{e} 3$ & $6.836 \mathrm{e} 4$ & $4.9 \mathrm{hrs}$ \\
\hline 550 & $9.585 \mathrm{e} 4$ & $2.324 \mathrm{e} 3$ & $9.352 \mathrm{e} 4$ & $6.2 \mathrm{hrs}$ \\
\hline 850 & $1.467 \mathrm{e} 5$ & $2.918 \mathrm{e} 3$ & $1.438 \mathrm{e} 5$ & $7.6 \mathrm{hrs}$ \\
\hline 1000 & $1.721 \mathrm{e} 5$ & $3.192 \mathrm{e} 3$ & $1.689 \mathrm{e} 5$ & $8.3 \mathrm{hrs}$ \\
\hline
\end{tabular}

Table 4: PID parameters for $\mathrm{T}_{\mathrm{g}}$ by tuning methods function, IAE + $\lambda I S U$

(equ. 8) has higher level of optimisation mechanism and better dynamic response than improved bound. The application of $\lambda$ with ISU has suppressed the oscillatory behaviour of glass temperature response by smoothes the controlled variable responses. Overall desired response characteristics, which are reduction of set-point error, overshoot and settling time, are achieved with the IAE + $\lambda I S U$.

\begin{tabular}{|c|c|c|c|c|c|}
\hline Tuning Methods & $\boldsymbol{K}_{\boldsymbol{P}}$ & $\boldsymbol{K}_{\boldsymbol{l}}$ & $\boldsymbol{K}_{\boldsymbol{D}}$ & $\begin{array}{c}\text { Set-point } \\
\text { Error }\end{array}$ & $\boldsymbol{T s} \mathbf{( 2 \% )}$ \\
\hline Direct Synthesis & $2.235 \mathrm{e}-3$ & $5.15 \mathrm{e}-5$ & 3.563 & $1.981 \mathrm{e}^{5}$ & $40 \mathrm{hrs}$ \\
\hline Improved Bound SGAs & $3.675 \mathrm{e}-3$ & $2.54 \mathrm{e}-5$ & 6.322 & $8.438 \mathrm{e}^{4}$ & $30 \mathrm{hrs}$ \\
\hline Weighting Factor SGAs & $9.863 \mathrm{e}-3$ & $9.461 \mathrm{e}-6$ & 7.358 & $7.029 \mathrm{e}^{4}$ & $4.9 \mathrm{hrs}$ \\
\hline
\end{tabular}

\section{DISCRETE CONTROL STRATEGIES ON REALISTIC MODEL BY DECENTRALISED TECHNIQUE}

Discrete PID controllers would be applied in loop interactions associated with the $2 \times 2$ multivariable glass furnace processes as shown in figure 5. Individually optimised discrete control parameters by SGAs with the respective control oriented models are applied in the decentralising control scheme at the multivariable realistic models. By applying closed-loop step input on both $\mathrm{EO}_{2}$ and $\mathrm{T}_{\mathrm{SET}}$ will be tested to

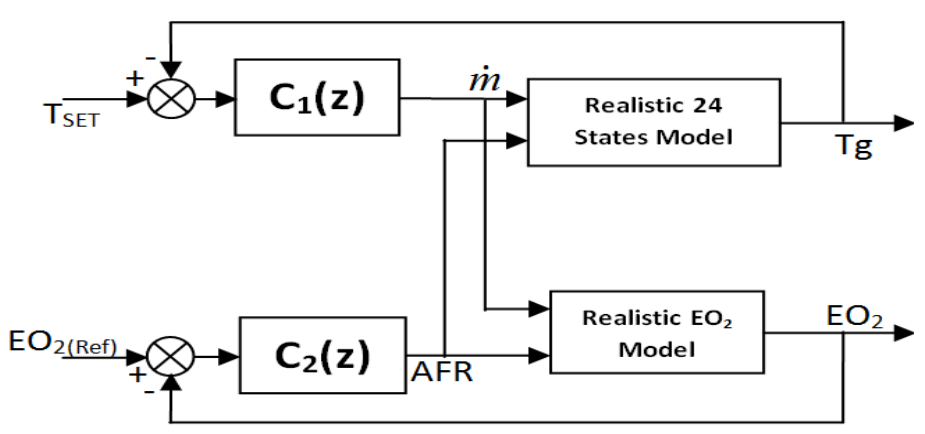

Figure 5: 2-input, 2-output multivariable glass furnace under closed-loop discrete PID controller 
analyse the affect of loop interaction within the realistic models on fuel consumption and thermal efficiency. Under closed-loop steady-state glass temperature $\left(T_{S E T}=1550^{\circ} \mathrm{K}\right)$, air ratio $17.2(0.05028 \mathrm{~kg} / \mathrm{s})$ and the fuel consumption is $0.002923 \mathrm{~kg} / \mathrm{s}$.

Simulation results of figure 6 and 7 illustrates that, under closed-loop step input of multivariable loop interaction are elaborated as follows:

1. $\mathrm{EO}_{2}(2.45 \%)$ constant; $\mathrm{T}_{\mathrm{SET}}=1550^{\circ} \mathrm{K}$ to $1580^{\circ} \mathrm{K}-$ The fuel consumption is increased to $0.003034 \mathrm{~kg} / \mathrm{s}$ as an increase in TSET. To obey an increase in fuel ratio, the air ratio is increased to $0.05218 \mathrm{~kg} / \mathrm{s}$ while maintaining AFR (17.2) and $\mathrm{EO}_{2}$.

2. $\mathrm{EO}_{2}(2.45 \%)$ constant; $\mathrm{T}_{\mathrm{SET}}=1550^{\circ} \mathrm{K}$ to $1530^{\circ} \mathrm{K}$ - The fuel consumption is decreased to $0.002811 \mathrm{~kg} / \mathrm{s}$ as a decrease in $\mathrm{T}_{\mathrm{SET}}$. To obey a decrease in fuel ratio, the air ratio is decreased to $0.04834 \mathrm{~kg} / \mathrm{s}$ while maintaining AFR (17.2) and $\mathrm{EO}_{2}$.

3. $\mathrm{T}_{\mathrm{SET}}\left(1550^{\circ} \mathrm{K}\right)$ constant; $\mathrm{EO}_{2}=2.45 \%$ to $3 \%$ - The AFR is increased to 17.78 as an increases in $\mathrm{EO}_{2}$. To obey an increase in $\mathrm{AFR}$, the air ratio and fuel ratio are increased to $0.0531 \mathrm{~kg} / \mathrm{s}$ and $0.002987 \mathrm{~kg} / \mathrm{s}$ while maintaining $T_{\text {SET }}$.

4. $\mathrm{T}_{\mathrm{SET}}\left(1550^{\circ} \mathrm{K}\right)$ constant; $\mathrm{EO}_{2}=2.45 \%$ to $2 \%$ - The AFR is decreased to 16.75 as a decreases in $\mathrm{EO}_{2}$. To obey a decrease in AFR, the air ratio and fuel ratio are decreased to $0.04732 \mathrm{~kg} / \mathrm{s}$ and $0.002824 \mathrm{~kg} / \mathrm{s}$ while maintaining $\mathrm{T}_{\mathrm{SET}}$.

Simulation results reveals that any change in $T_{S E T}$ is varying the fuel consumption and excess air accordingly while sustaining the $\mathrm{EO}_{2}$. As shown in figure 6 , the both closed-loop step-up and step-down responses of $\mathrm{EO}_{2}$ completely overlapped and describes that the responses are not affected at all by loop interaction of $\mathrm{C}_{\mathrm{g}}$ as illustrated in figure 1. But, the $\Delta \dot{m}$ loop interaction is still needed to $\mathrm{EO}_{2}$ model for AFR synchronisation.

On other hand, any variations in $\mathrm{EO}_{2}$ have an insignificant affect glass furnace process. According to realistic glass furnace model in figure 1, the AFR has a weak loop interaction with glass temperature model through nonlinear algebraic expression of $f_{1}$. Simulation results as in figure 7 reveals that when step inputs of $\mathrm{EO}_{2}$ are changed at $16.67 \mathrm{hrs}$, the $\mathrm{T}_{\mathrm{g}}$ response is varies about $1^{\circ} \mathrm{K}$ under closelooped condition. Due to nonlinearity effect of $f_{1}$ and

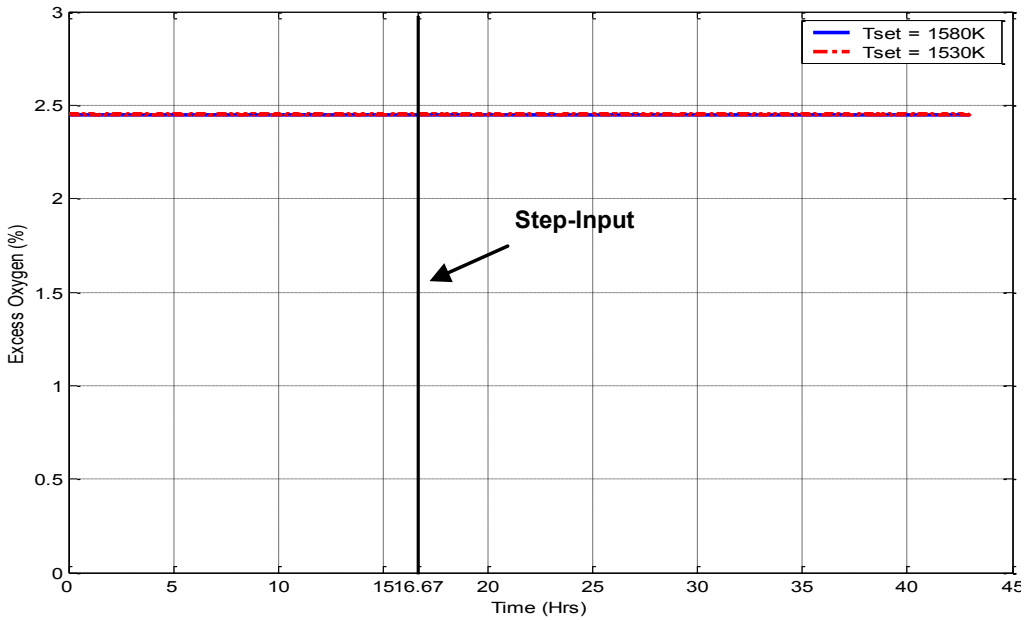

Figure 6: Closed-loop transient responses of $\mathrm{EO}_{2}$

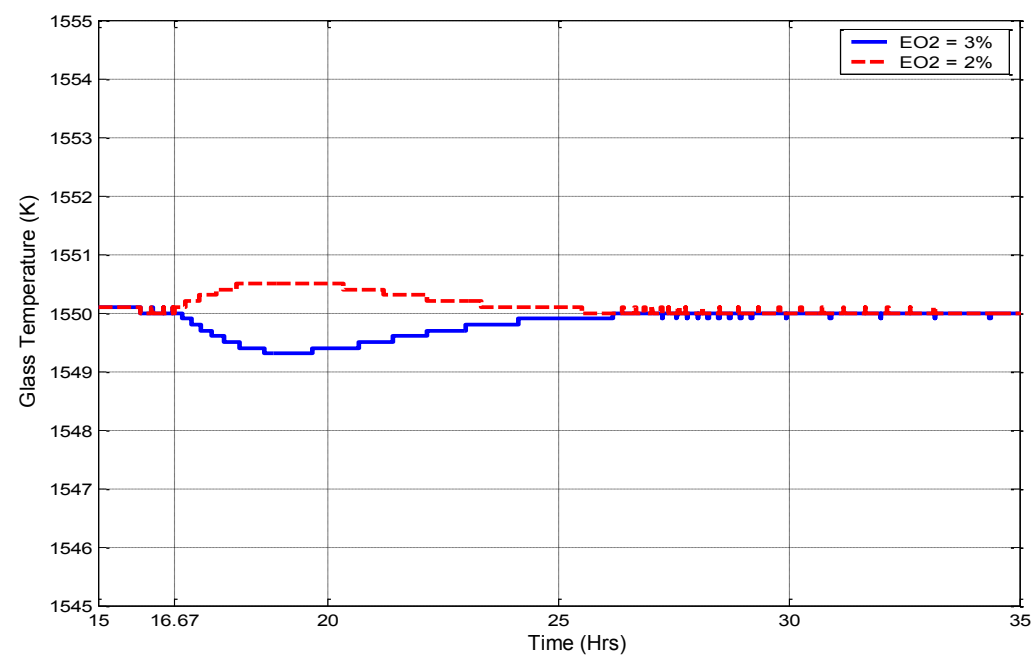

Figure 7: Closed-loop transient responses of $\mathrm{T}_{\mathrm{g}}$ long dynamic responses the AFR, air ratio and fuel ratio are changed accordingly to sustain the $T_{g}$ after $2 h r s$ of step inputs.

Under open-loop condition, an increase and a decrease in air ratio is appeared a reduction and a rise in glass temperature, respectively. In actual condition, high excess air 
ratio will blow-away the heat from combustion chamber [17]. Simulation results of figure 8 and table 5 illustrates that by reducing the $\mathrm{EO}_{2}$, the overall steady-state fuel consumption is reduced about $3.4 \%$ while sustaining the glass temperature set-point at $1550^{\circ} \mathrm{K}$.

According to the environmental agencies combustion guideline, the maximum permitted level of $\mathrm{EO}_{2}$ is $3 \%$. The optimum thermal efficiency of combustion process is within the range of $1.5 \%$ to $3 \%$ of $\mathrm{EO}_{2}$, which is equivalent about $10 \%$ to $20 \%$ of excess air. Thus, reducing the $\mathrm{EO}_{2}$

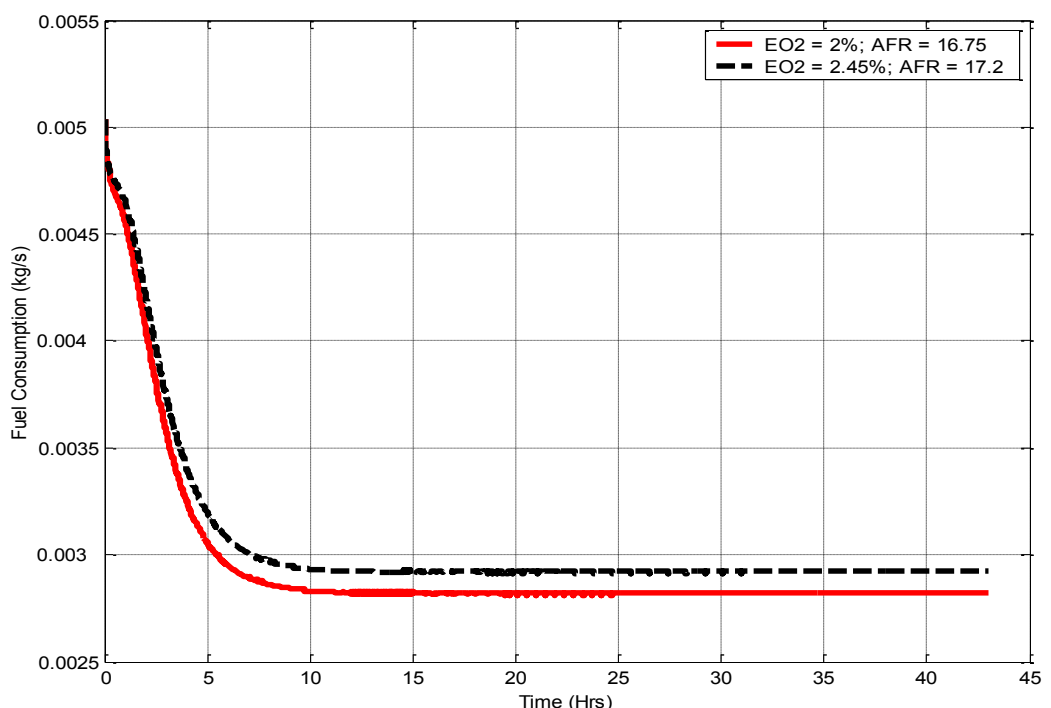

Fiqure 8: Fuel ratio consumption response of $\mathrm{EO}_{2}$

Table 5: Simulation result of fuel consumption

\begin{tabular}{|c|c|c|c|}
\hline $\begin{array}{c}\mathrm{EO}_{2} \\
(\%)\end{array}$ & $\begin{array}{c}\text { AFR } \\
\text { (Mass) }\end{array}$ & $\begin{array}{c}\text { Closed-Loop Steady } \\
\text { State Fuel Flow (kg/sec) }\end{array}$ & $\begin{array}{c}\text { Fuel Consumption (kg) } \\
\text { (24 Hrs Operation) }\end{array}$ \\
\hline 2.45 & 17.2 & 0.002923 & 252.55 \\
\hline 2 & 16.75 & 0.002824 & 243.99 \\
\hline
\end{tabular}
within the optimum region and automatic monitoring of excess oxygen model will be beneficial for minimising the undesirable emissions and fuel consumption while sustaining the thermal efficiency of combustion.

\section{CONCLUSIONS AND FUTURE WORK}

An application of SGAs in optimising the discrete PID controllers for realistic multivariable glass furnace has been demonstrated. According to the desired response characteristics, the control parameters optimisation is enhanced with personalised cost function and improved searching boundaries. The loop interaction within realistic multivariable glass furnace is compensated with well optimised PID parameters by SGAs in decentralised technique. An automatic continuous monitoring of $\mathrm{EO}_{2}$ would enhance the overall performance of multivariable glass furnace. Future work will be carried out in optimising discrete controller for the extended multivariable realistic model in multistage model by SGAs.

\section{REFERENCES}

[1] Scottish Environment Protection Agency (SEPA), Guidance for Monitoring Enclosed Landfil Gas Flares, Report No. GEHO1104BHZI-E-P, 2005.

[2] T.J. Monica, C.C. Yu and W.L. Luyben "Improved Multiloop Single-Input/SingleOuput (SISO) Controller for Multivriable Process”, Ind. Eng. Chem. Res., vol.27, pp. 969973, 1998.

[3] M. Hovd and S. Skogestad, "Sequential Design of Decentralised Controllers", Automatica, vol. 30 (10), pp. 1601-1607, 1994.

[4] J. Lee, W. Cho and T.F. Edger, "Multiloop PI Controller Tuning for Interacting Multivariable Processes", Comput. Chem. Eng., vol. 22 (11), pp.1711-1723, 1998.

[5] H.P. Huang, J.C. Jeng, C.H. Chiang and W. Pan, "A Direct Method for Decentralised PI/PID Controller Design”, J. Process Control, vol. 13 (8), pp. 769-786, 2003.

[6] P. Grosdidier and M. Morari, "A computer aided methodology for the design of decentralised controllers," Compt. Chem. Eng., vol. 11, pp. 423-433, 1987. 
[7] N.L.V. Truong, H. Seungtaek, and M. Lee, "Analytical Design of Robust Multiloop PI Controller for Multivariable Process," ICCAS-SICE Inter. Joint Conference, pp. 2961-2966, 2009.

[8] P. Wong and D.P. Kwok, "Optimal design of PID process controllers based on genetic algorithms", Control Eng. Prac., vol. 2(4), pp. 641-648.

[9] P.K. Viswanathan, W.K. Toh and G.P. Rangaiah, "Closed-Loop Identification of TITO Processes Using Time-Domain Curve Fitting and Genetic Algorithms", Ind. Eng. Chem. Res., vol. 40 (13), pp. 2818-2826, 2001.

[10]R. Bandyopadhyay, U.K. Chakraborty and D. Patranabis, "Autotuning a PID Controller: A Fuzzy-Genetic Approach", J. Syst. Architecht., vol. 47, pp. 663-673, 2001.

[11]C. Vlachos, D. Williams and J.B. Gomm, "Genetic approach to decentralised PI controller tuning for multivariable processes," IEE Proc.-Control Theory Appl., vol. 146(1), pp. 58-64, 1999.

[12]D. Li, F. Gao, Y. Xue and C. Lu, "Optimisation of Decentralised PI/PID Controllers based on Genetic Algorithm", Asian Journal of Control, vol. 3 (3), pp. 306-316, 2007.

[13]H.A. Morris, "Advanced modelling for small glass furnaces," Master's Thesis, Department of Mechanical Engineering, West Virginia University, Morgantown, USA, 2007.

[14]A.R. Holladay, "Modelling and control of a small glass furnace," Master's Thesis, Department of Mechanical Engineering, West Virginia University, Morgantown, USA, 2005.

[15]G. F. Franklin, J. D. Powell and M. Workman, "Digital Control of Dynamic Systems", Third Edition, Addison Wesley Longman, 1998.

[16]J. Gaffney, D.A. Green and C.E.M. Pearce, "Binary Vs Real Coding for Genetic Algorithm: A False Dichotomy?”, J. EMAC, vol. 51, pp. C347-C359, 2010.

[17] S.C. Carniglia and G.L. Barna, "Handbook of Industrial Refractories Technology Principles, Types, Properties and Applications," Noyes Publications, USA, 1992.

\section{ABOUT THE AUTHORS}

K. Rajarathianm, is a PhD student researching Advanced Control Techniques, with the Control Systems Group part of the Mechanical Engineering and Materials Research Centre (MEMARC), School of Engineering, Liverpool John Moores University, UK. E-mail: K.Rajarathinam@2011.ljmu.ac.uk.

Dr. J. Barry Gomm, Reader in Intelligent Systems, Control Systems Group, Mechanical Engineering and Materials Research Centre (MEMARC), School of Engineering, Liverpool John Moores University, UK. E-mail: j.b.gomm@ljmu.ac.uk.

Dr. Karl O. Jones, Principal Lecturer, Control Systems Group, Mechanical Engineering and Materials Research Centre (MEMARC), School of Engineering, Liverpool John Moores University, UK. E-mail: k.o.jones@ljmu.ac.uk.

Ahmed Saad Abdelhadi, is a PhD student researching Nonlinear pH System Identification and Control Optimisation, Control Systems Group, Mechanical Engineering and Materials Research Centre (MEMARC), School of Engineering, Liverpool John Moores University, UK. E-mail: a.s.abdelhadi@2012.ljmu.ac.uk. 